\title{
INTEGRATED SURVEY PROCEDURES FOR THE VIRTUAL READING AND FRUITION OF HISTORICAL BUILDINGS
}

\author{
S. Scandurra ${ }^{\text {a }}$, M. Pulcrano ${ }^{\text {a }}$, V. Cirillo ${ }^{\text {b }}$, M. Campi ${ }^{\text {a }}$, A. di Luggo ${ }^{a}$, O. Zerlenga ${ }^{b}$ \\ ${ }^{\text {a }}$ Department of Architecture, University of Naples Federico II, (simona.scandurra, margherita.pulcrano, campi, \\ antonella.diluggo)@unina.it \\ ${ }^{\mathrm{b}}$ Department of Architecture and Industrial Design, University of Campania Luigi Vanvitelli, (vincenzo.cirillo, \\ ornella.zerlenga)@unicampania.it
}

Commission II, WG II/8

KEY WORDS: Range-based survey, Image-based survey, 3D Modelling, H-BIM, Virtual Tour

\begin{abstract}
:
This paper presents the developments of research related to the integration of digital survey methodologies with reference to imagebased and range-based technologies. Starting from the processing of point clouds, the data were processed for both the geometric interpretation of the space as well as production of three-dimensional models that describe the constitutive and morphological relationships. The subject of the study was the church of San Carlo all'Arena in Naples (Italy), with a HBIM model being produced that is semantically consistent with the real building. Starting from the data acquired, a visualization system was created for the virtual exploration of the building.
\end{abstract}

\section{INTRODUCTION}

Current surveying instruments, whether they are active or passive optical sensors, represent a fundamental support to the knowledge of a building whose use has implicitly determined a renewed attention to the historical architectural heritage, foreshadowing new points of view and ways of reading it. Nowadays, it is possible to analyse an artefact by studying it in its virtual copy, with it also being possible to count on the availability of a 3D model that can be manipulated and read on different scales.

It is worth noting how the possibility to acquire a great deal of data in a relatively short space of time has given a considerable impulse to the documentation of architectural heritage, while also allowing for parallel experimentation of integrated procedures for the recovery, processing and return of data. Thus, resulting in a virtual 3D cast rendered in a point cloud, that is a set of relative coordinates arranged in the three-dimensional digital space, referring to a high number of representative points of the surface of what has been surveyed. In the case of image-based procedures, these are point-like models returned through the acquisition and post-production of photographic images. Whereas, with range-based instruments, the point cloud is directly the set of measurements acquired by the instrument through the emission of an electromagnetic signal.

The subject of this paper is the survey carried out on the church of San Carlo all'Arena in Naples, which is an interesting example of Baroque architecture defined by an oval layout as a geometric reference matrix of the entire space used.

The construction of the church, the work of the Dominican monk Fra' Nuvolo, began in 1626 and was only completed in 1680 due to the difficulties related to the construction of the dome, that is as large as it is unique for the period. The interior is made up of a single large hall, with the perimeter being punctuated by lateral chapels which are symmetrically arranged with respect to the longitudinal axis.

It is worth highlighting how the identification of the geometry, intended as a work hypothesis but also as a result of the same, has allowed to reduce the complexity of such a highly articulated space to a scheme closely related to its compositional values. (A.d.L.)

\section{RELATED WORKS AND AIMS}

In recent years, numerous research projects have been developed linked to the knowledge and documentation of architectural heritage, experimenting with latest-generation surveying methods as well as using different types of sensors, from active ones referring to laser scanners (TLS), to passive ones such as photogrammetry. These studies have also made it possible to compare the peculiarities and specificities of the different procedures, with the possibility to obtain the maximum benefit from current hardware and software technologies (Remondino et al., 2017).

The various experiments have led to significant developments in terms of precision, accuracy, costs, acquisition times and data processing (Remondino, et al. 2014; Apollonio et al., 2014; Fassi, et al., 2013). These studies constitute the theoretical and methodological foundation of this paper, which is also based on the previous experience of the working group that has carried out on the most representative monuments of the city of Naples and the surrounding area, using different types of tools and techniques (Laser scanners, UAV, digital photogrammetry and Lidar). The authors have carried out numerous studies in this research area, in collaboration with international teams producing studies and research in the field of range-based and image-based surveying and documentation of historical buildings.

The aim of this work is to produce a geometric reading starting from the elaboration and processing of point clouds obtained through the integration of laser scanner surveys and photomodelling (De Luca L., 2011).

An analysis methodology was created that aims to identify the geometrical configuration of the layout, to then be specified in the study of the details and elements that design the space, analysing the close correlation between the plane matrix and the spatial conformation, with particular reference to the ceiling, 
reinforcing the suggestion of a single space drawn by several timely and iterated grammatical elements. (M.C.)

\section{INTEGRATION OF RANGE-BASED AND IMAGE- BASED METHODS, POINT CLOUD PROCESSING AND COMPARING}

Considering the shape of the space, it was decided to carry out a laser scanner survey using a Faro Focus 3D ms120 which has a maximum measurement range of $120 \mathrm{~m}$ nominal distance and measures a distance with a precision of the order of $\pm 2 \mathrm{~mm}$ over $25 \mathrm{~m}$.

The design phase of the survey, relating to the identification of the scanner station points and the position of the targets, was preceded by a careful reading of the space, defined by a single central-planted vault on an ovate base, which includes the hall and the high altar, which is surmounted by an extrados dome. On the perimeter, there are seven chapels, three on each side with an additional seventh on the major axis, in correspondence to the altar. Considering the interior furnishings of the church as well as the rich decorative elements and presence of the chapels, it was decided not to limit the survey to a single scan from a central station point, but rather to carry out more scans, thus avoiding excessive shadow areas. A single central scan would not have guaranteed the complete identification of the design of the flooring, the acquisition of the area behind the altar or an adequate reading at the entrance. 14 station points were therefore identified (one in the centre of the hall, three around the main altar, six in correspondence to each chapel, one inside the first right chapel and three along the path that connects the outside to the internal space) for a total of 316,510,357 registered points.

The number of points and acquisition times is derived from the settings established in the campaign phase, providing a degree of overlap between the scans so as to obtain a dense overall cloud relatively quickly. The scanner was set up with a scanning step of $6.136 \mathrm{~mm}$ over $10 \mathrm{~m}$, while for the scans in correspondence to the chapels, considering that for smaller distances even a lower resolution allows for a high level of information, the scan was set with a pitch of $12 \mathrm{~mm}$ over $10 \mathrm{~m}$. The scanning times of the clouds were respectively about $7^{\prime}$ and 5 ', for a total surveying time of $1 \mathrm{hr} 30 \mathrm{mins}$.

For all the scans, it was chosen to record the colour data expressed by RGB code through the photographic acquisition contextual to the scan (a 70megapixel camera that integrates the scanner, automatically superimposes the colour without generating parallaxes, returning a cloud of photorealistic 3D points).

For the editing and alignment of the scans, the Faro Scene software was used. To have greater control over the final model, the alignment of the clouds occurred in semi-automated mode, verifying the overlap and recognition of the bi and tridimensional targets (chessboards and spheres) placed in the environment during the acquisition phase. A post-processing phase was used to reduce noise as well as clean-up any individual clouds, making detailed investigations where necessary.

Shade areas were found in some areas inside the chapels, which were mainly due to the presence of gates and entrance balustrades. The degree of detail is more than valid with regard to the morphology of the space, but not always sufficient in correspondence to the sculptural mouldings or inlays. It was therefore decided to integrate the range-based point clouds with image-based detail acquisitions that would be useful for the 3D reconstruction of the moulded elements, altars and, in particular, the sculpture of Christ by M. Naccherino in the central chapel right.

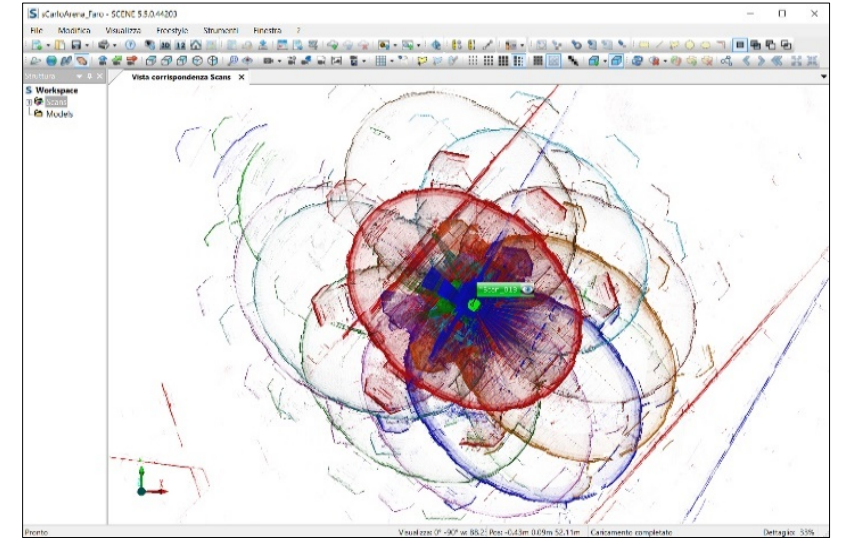

Figure 1. Point cloud in Faro Scene.

The first operation of these surveys was to organize the in-situ photographs. Since most of them are non-isolated objects, it was decided to use the parallel axis technique, integrated with the convergent axis technique (De Luca L., 2011). A 20 megapixel Nikon Coolpix L330 bridge camera was used, were is not possible to change the lens. The minimum zoom was therefore set for the survey of the near objects and on average for the survey of distant objects, evaluating a number of frames useful to guarantee a high level of detail and, for each of the sets, an overlap between the successive images of about $70 \%$.

The software used to process the images was PhotoScan Professional produced by Agisoft, which uses SFM (Structure for Motion), which is an orientation strategy of Computer Vision interested in the automation in the generation of 3D models.

The most delicate phase of the photo-modelling was the image orientation, with the identification of the common points and relative orientation (the Agisoft Lens application was used to generate the calibration parameters of the camera, i.e. for the correction of internal distortions in the device). Despite the increasing automation of the applications dedicated to these processes, the accuracy of the result depends greatly on the attention placed during the image acquisition phase.

In this case, being small objects, the photographic sets never exceeded 40 photographs and, not wanting to compromise the photographic yield with subsequent manipulations, it was preferred to avoid the use of targets, although they could facilitate the automatism of the software. This led to a slight criticality in the case of the survey of the Christ, since it consists of curved and homogeneous surfaces from a chromatic point of view. For this reason, it was necessary to identify the correspondences in a timely manner as well as include a greater overlap between the frames. On the contrary, despite the poor lighting conditions, the image orientation for the altars was immediately successful.

PhotoScan built a cloud of scattered points in conjunction with the alignment phase. Subsequently, it was possible to densify the cloud points (dense cloud) and generate mesh surfaces, until the textures were affixed, finally obtaining a high-resolution 3D result with photorealistic rendering.

For the scaling of the photogrammetric models, data that had already been acquired by laser scanning were used.

The photo-modelling allowed to fill the shade areas as well as those that had not been acquired by the laser, obtaining, through the integration of data, high levels in the final output phase. It should be noted how the point clouds generated by the two systems are quite different, while with the laser scanner it is possible to predict the step of the points that will represent a surface, with the photo-modelling a data loss is obtained depending on the degree of reading of the images. 


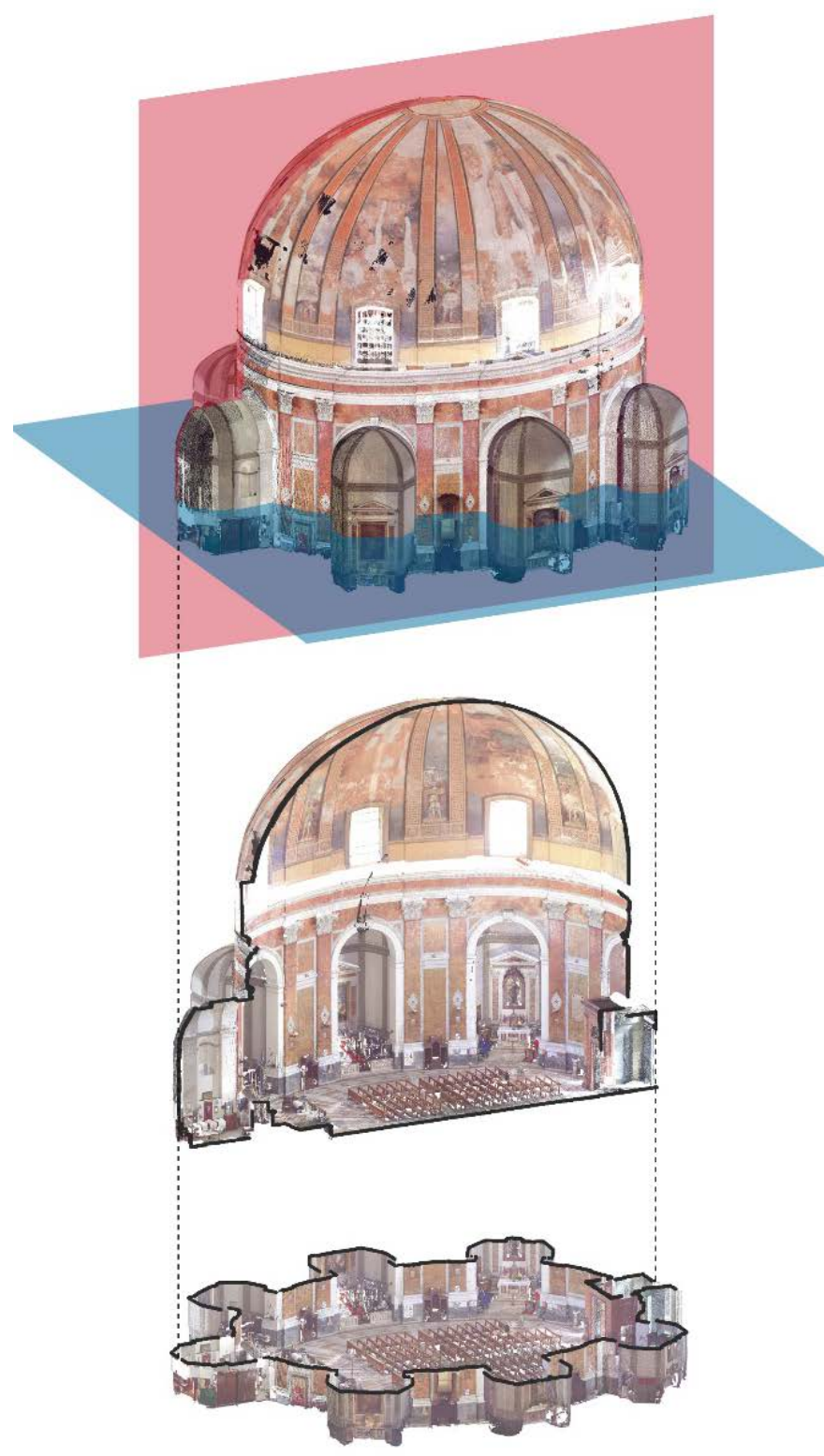

Figure 2. Point cloud: 3D section and plan.

The data obtained can be combined into a single result. For example, Cloud Compare SW makes it possible to easily overlap, starting from the automatic or manual identification of the common points among multiple clouds.

It is also worth highlighting how the 3D model (point cloud), despite its realistic appearance and high metric value, is still an uncritical model, which imposes, after the acquisition phase, carrying out a critical interpretation of the forms and consistency of the actual artefact in a digital environment. (S.S.)

\section{GEOMETRIC ANALYSIS}

The main geometric feature, which emerges from the analysis of the architectural survey of the church of San Carlo all'Arena, is the ovate shape of the planimetric profile. This geometric form is the genesis of the entire spatial layout. The use of this geometric form is not unique in the panorama of the Neapolitan ecclesiastical architectural heritage. During the seventeenth century, several Neapolitan churches were built or renovated according to an oval planimetric layout, including: San Sebastiano (restored by G. Nuvolo and demolished in the 20th century); Santa Maria Egiziaca in Forcella (1684); Santa Maria di Caravaggio (1627).

From a formal point of view, a flat ovate shape is characterized by a curvilinear profile with double orthogonal symmetry. From a geometrical-mathematical point of view, an ovate shape can be circumscribed either in a polycentric curve (with four or more centres), in an ellipse or in two curved lines that are similar but distinct in the theoretical-scientific foundation. A polycentric curve with an ovate shape is a flat figure generated by the succession of several circumference arcs, whose contact points must satisfy the continuity property. Theoretically, this curve belongs to the branch of Elementary Geometry according to which complex figures are obtained by derivation from the line and circle through elementary geometric constructions, with the aid of the line and a compass. An elliptic curve, on the other hand, is a geometric place of the points of the plane satisfying specific relations. The ellipse is a convex, continuous and closed plane curve, geometric place of the points of the plane such that the sum of the distances from two fixed points, called fires, is constant and equal to the dimension of the major axis. Its theoretical foundation is in the Theory of Conic Sections.

It has long been debated whether, respectively, in antiquity and the Baroque period, the oval planimetric layouts of amphitheatres and churches were made on the ground using geometric constructions based on the theory of polycentric or conical curves. Digital survey studies of several examples have not always been able to answer the question unequivocally. With the same dimension of the axes (minor and major) of ovate curves drawn as polycentric or ellipse, the checks made by the digital overlapping of the profiles have shown that both curves approximate the mutually oval path to each other, so as to make the belonging to the different geometrical-mathematical species irrelevant on a formal level, especially when the polycentric curve varies from four to eight centres (Migliari, 2009).

With regard to the oval shape of the planimetric profile of the church of San Carlo all'Arena, three considerations can be put forward on the basis of the survey: a) interpolating several significant points of the ovate profile of the church, the curve obtained corresponds to the criterion of tracing a polycentric figure with size of the axes (minor axis, equal to 21.12 metres, major, equal to 27.24 meters); b) resorting to the elementary geometric constructions on the tracing of an ovate shape to four centres, the curve measured is very close to the fourth "rule" published by Sebastiano Serlio in the "First Book" of the Trattato di Architettura (Treaty of Architecture) (Paris, 1545, pp. 13v -14) and it allows us to hypothesize that Fra Nuvolo knew the Treaty of Serlio; c) with the same dimensions of the axes, overlapping both the polycentric curve drawn according to the fourth rule of Serlio and an ellipse, the differences between the two profiles and those of the curve obtained from the survey are negligible and the approximations, which can be found near the points of the polycentric curve, are of the order of a few centimetres - 0.06 metres - (Fig. 3).

Another interesting consideration on the basis of the ovate profile obtained from the survey regards the relationship between geometric formalism (which connotes analytical geometry) and the concept of eccentricity of the ellipse. It is well-known how the ellipse is defined by a second-order equation (called canonical) according to which: «given a plane $\alpha$ and two numbers, a and c, positive and such that a $>\mathrm{c}$, and said F1 and F2 two points of $\alpha$ such that F1F2 $=2$ c, we define ellipse of fires F1 and F2 the set of points $P$ such that we have $(\mathrm{PF} 1)+(\mathrm{PF} 2)=2 \mathrm{a}$. It is shown that, by choosing an orthogonal monometric reference having for a unit of measure $\mathrm{u}$ for axes $\mathrm{x}$ and $\mathrm{y}$ respectively, the 


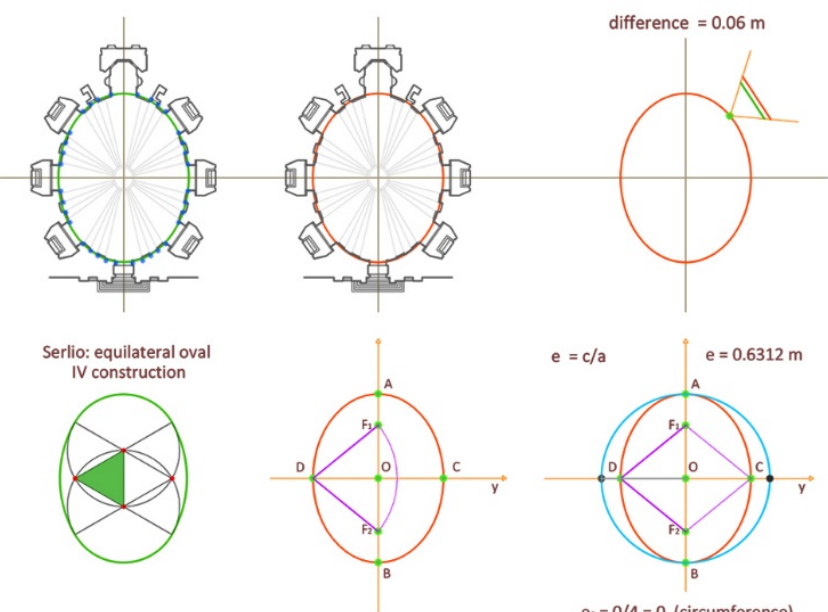

$e_{0}=0 / 4=0$ (circumference)
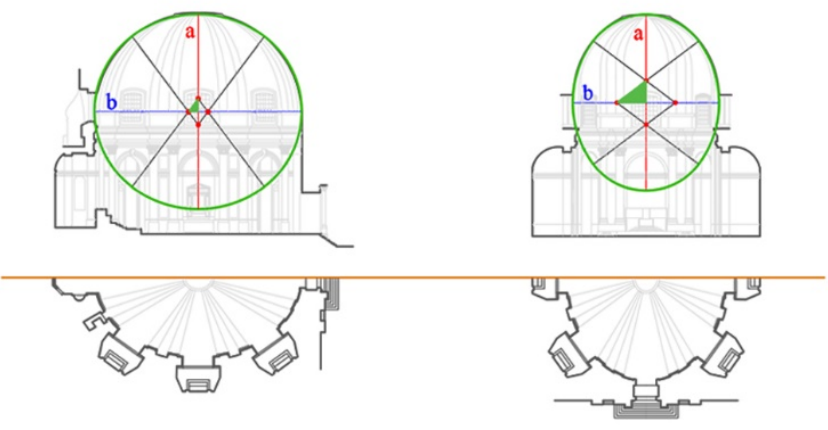

Figure 3. Geometric Analysis

line F1F2 and the axis of the segment F1F2, the ellipse is represented by the equation:

$$
\mathrm{x} 2 / \mathrm{a} 2+\mathrm{y} 2 / \mathrm{b} 2=1
$$

with (b2 = a2 - c2), that is a point $\mathrm{P}(\mathrm{x}, \mathrm{y})$ belongs to the ellipse if and only if $(\mathrm{x}, \mathrm{y})$ is a solution of the equation» (Antonucci, pp. 105-106). In particular: for $x=0$, it results $y= \pm b$; for $y=0, x=$ $\pm \mathrm{a}$. Therefore, the values a and $\mathrm{b}$ correspond to the measurements of the ellipsis of the ellipse, respectively major and minor, and the curve turns out to be symmetrical with respect to the two axes (double orthogonal symmetry). The c/a ratio defines the eccentricity of the curve, a numerical value that is always smaller than the unit for the ellipse. The eccentricity is indicative of the formal value of the curve: the more the value grows, the more the fires move away from the centre, the more the profile of the ellipse appears flattened and oblong; vice versa, the more the value decreases, the closer the fires approach the centre, the more the profile of the ellipse appears round. At the limit, if the eccentricity of the curve is null ( $c=0$ ), the fires coincide with the centre and the ellipse turns into a circle. In fact, for $\mathrm{c}=0$ it is easy to verify that:

$$
\mathrm{c} 2=\mathrm{a} 2-\mathrm{b} 2 ; 0=\mathrm{a} 2-\mathrm{b} 2 ; \mathrm{a} 2=\mathrm{b} 2 ; \mathrm{a}=\mathrm{b} .
$$

Calculating the eccentricity of the ellipse that approximates the ovate form obtained from the survey of the church of San Carlo all'Arena, it is verified that it is equal to 0.6312 . Therefore, the planimetric profile appears rather oblong in the longitudinal direction, favouring a perceptual crushing effect along the transverse axis and of greater visual depth along the entrancealtar path. (O.Z.)

\section{SPATIAL MORPHOLOGY AND 3D MODELLING}

A 3D modelling was carried out on the basis of the survey, followed by a visualization oriented to the geometric analysis of the spatial layout of the church of San Carlo all'Arena. The restitution and analysis of the three-dimensional geometric model was realized with a commercial application software for the 3D modelling of sculptural surfaces or free form (Rhinoceros). In this software, all the geometric entities are NURBS (Nonuniform Rational B-Splines) mathematical representations, with which it is possible to define both 2D and 3D geometries (lines and surfaces), notable (such as conics and quadrics) and free form (a hull or bodywork). In this sense, through a computerized description for algorithms, the NURBS surfaces (also called interpolation surfaces) represent a generalization of the surfaces treated in classical geometry and lend themselves to numerous, important and new applications (Migliari, 2003).

The ovate matrix, which characterizes the planimetric profile of the church of San Carlo all'Arena, is the configurative origin of the entire spatial layout, both inside and outside, being the extrados dome. The ovate curve, which approximates the planimetric profile obtained from the survey, has been assumed as a dimensional model and genesis of the three-dimensional modelling of the church. In this sense, the spatial layout of the church can be traced back to a geometric model composed of a straight cylinder and a basins vault on ovate plant. The straight cylinder has an ovate base and is 15.76 metres high, including the entablature. The geometric model of this cylinder corresponds to a translation surface where the generating curve (oval) translates along the vertical direction (z-axis). In this ovate cylinder, there are six lateral chapels, distributed according to the double orthogonal symmetry and whose connecting arcs are humped curves drawn on the surface of the cylinder.

The basins vault on ovate plant does not sit directly on the entablature but rather on a moulded strip, 1.93 metres high. This serves to give greater impetus to the basins vault which, compared to the impost, is 12.95 metres high. In this strip (as well as partly in the dome) they are seven large windows. These windows rest directly on the entablature corresponding vertically, six, to the underlying chapels and the seventh to the altar. The basins vault on ovate plant has been modelled referring to the surface obtained by interpolation of three ovals. Once the oval impost and the vault on the basin vault have been defined (equal to 8.55 meters), the two oval profiles deriving from the survey have been assigned, passing through the minor and major axis of the impost oval. At this point the geometric place of all the semi-oval shape thus formed is the three-axis ellipsoid, which constitutes the geometric model of the intrados of the basin vault on an oval plant (Donghi, 1925). It is noted that the difference between the model longitudinal section thus constructed and the surveyed curve does not exceed 0.07 meters, as for the cross section the difference does not exceed 0.20 meters.

In the three-dimensional modelling of the basins vault of the church of San Carlo all'Arena, reference was made to the geometric model of the three-axis ellipsoid ellipsoid (or called general ellipsoid) (Fig. 4). Comparing the geometric model of the three-axis ellipsoid with the survey of the church cloud, the differences appear negligible (maximum 6 millimeters at the sides).

From a decorative point of view, the basins vault has sixteen ribs, placed below the pilasters below; these ribs are also included in the ornamental design of the floor, as if they were the effect of an orthogonal projection. Another characteristic of the dome is the 

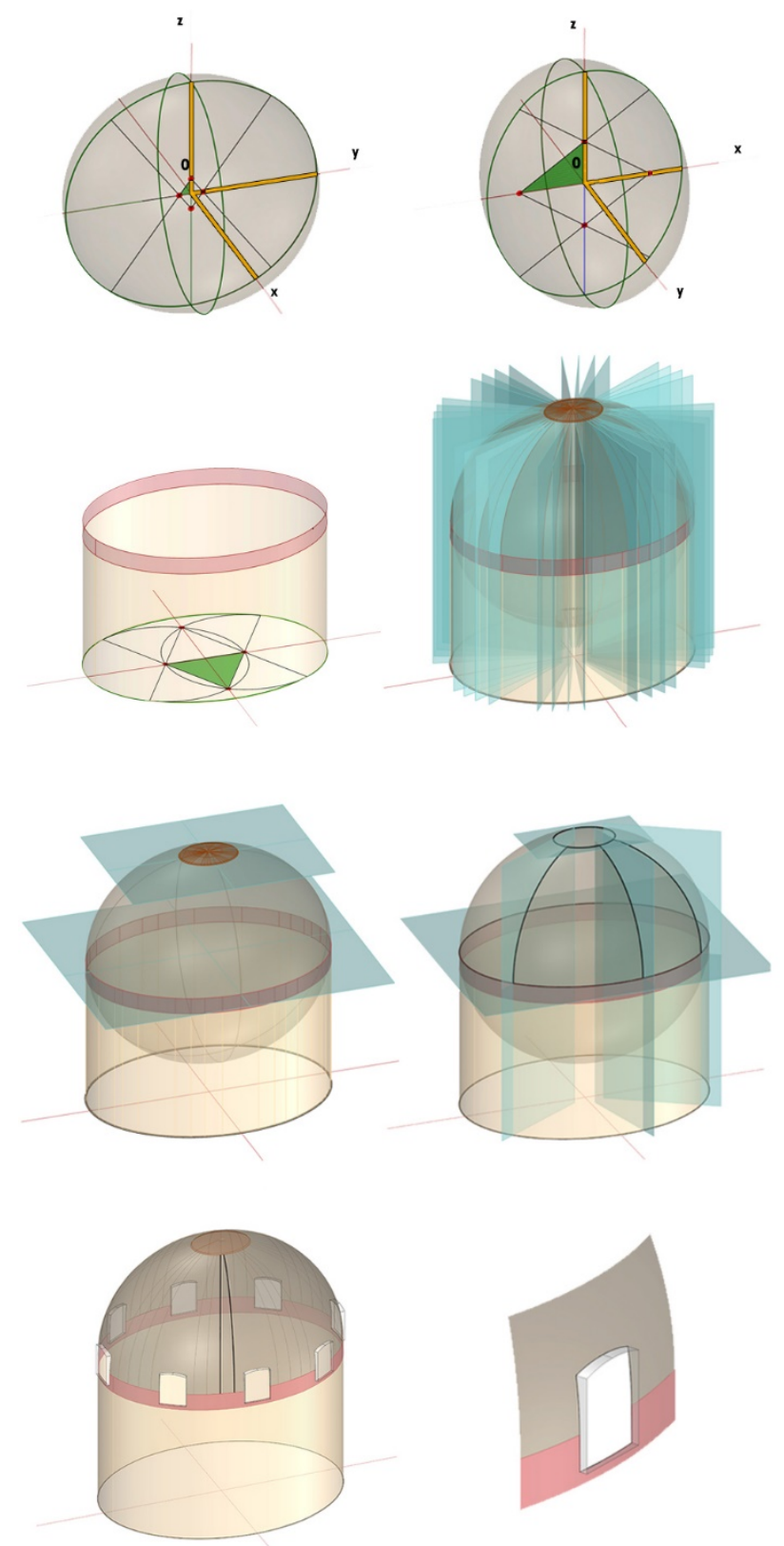

Figure 4. Geometric Analysis

presence of a central eye (also with an ovate profile), which projects onto the floor defining an oval decorated internally with a star of David, somewhat flattened in a transverse direction. Finally, for the part of the windows that open in the basins vault, in these the connecting arcs are hump curves drawn on the threeaxis ellipsoid surface, while in the transversal direction the piers have a rectilinear course, for the part that falls into the moulded band, and curved for the one that follows the surface of the basins vault. (V.C.)

\section{H-BIM MODELLING}

The model obtained from the survey by point clouds is not sufficient to document the object surveyed, despite the morphometric characteristics that it proposes to be exactly representative of the building. The point clouds simulate reality, reproducing the surface appearance, while maintaining the metric characteristics unaltered and without performing any discretization, reinterpretation or manipulation of the acquired data. If there is no syntactic re-elaboration, the meaning of what is detected risks losing the theoretical value that motivates it, reducing it to a mere technological experiment.

It is therefore necessary to take into account the fact that the result of the instrumental surveys aims at the digital repetition of the form with a high degree of detail, which, however, is not sufficient to define an architecture as such. An interpretation of the survey is needed so that the abundance of data of which it is composed is not collected in vain, with it being carried out through the classification of the categories of elements of which the artefact is composed, considering the general elements (walls, floors, structural elements, ...), the characteristic elements (doors, windows, ...) and the finishing elements (moulded profiles, style details, ...). This decomposition involves recognizing the parts that make up the work, ontologically distinct and analysed in their being, individually and in relation to the whole.

For some years, the use of three-dimensional data to support 3D information models that follow the logic of BIM - Building Information Modelling (di Luggo A., et al., 2016, di Luggo A., et al., 2017) has been tested at the Department of Architecture.

In the construction of these models, the systemic reading of the components of the work as well as the relationships between them is essential due to the logic underlying the modelling already being thought according to the semantic and ontological principles of the building.

Specifically, for the church of San Carlo all'Arena, it was decided to use the Autodesk Revit Architecture software as a BIM modeller, directly importing the point clouds, appropriately exported in .rcp format (Faro Scene exports directly in .rcp format. while, for the photo-modelled portions, the Autodesk Recap application was used to convert the .txt file to .rcp).

Even though Autodesk Revit allows for a certain flexibility in the modelling of families not already present in the official libraries, since it is not designed for historical architectures, it does not guarantee immediate or always effective solutions in the realization of all the portions necessary for the definition of the overall model. For example, it does not particularly lend itself to the irregularities typical of historical walls, requiring the identification of specific solutions that involve, in part, the loss of the link with the BIM elements immediately representative of the actual building.

Nevertheless, a BIM model of the historical building becomes an occasion to make available a true three-dimensional document of the work, capable of describing it through new parameters, not coded in graphic form but manageable through the alphanumeric databases strongly correlated to the representation data. This substance provides a rich tool for data reprocessing, which can be interrogated and, if necessary, themed. The elaboration logic at the base of these models is therefore highly rational and tends to avoid subjective and/or approximate results of synthesis. Thus, the instrumental survey carried out, not subject to a priori interpretations, becomes susceptible to enrichment and the $\mathrm{H}$ BIM (Heritage, Historical) model becomes a means for the multiplication, overlap and aggregation of data with a univocal meaning and, starting from point clouds, it aggregates information of a different nature (descriptive, metric, evolutionary, design, etc.).

The final aim is the construction of a document which can be easily used in relation to different technical-disciplinary needs, and, if on one hand, the info-graphic media changes, which is still linked to the traditional rules of representation, on the other, allows for a wide cultural dissemination in digital terms. The digitalization of the building through ITC should not be understood as a mere representation of real features, but rather a 


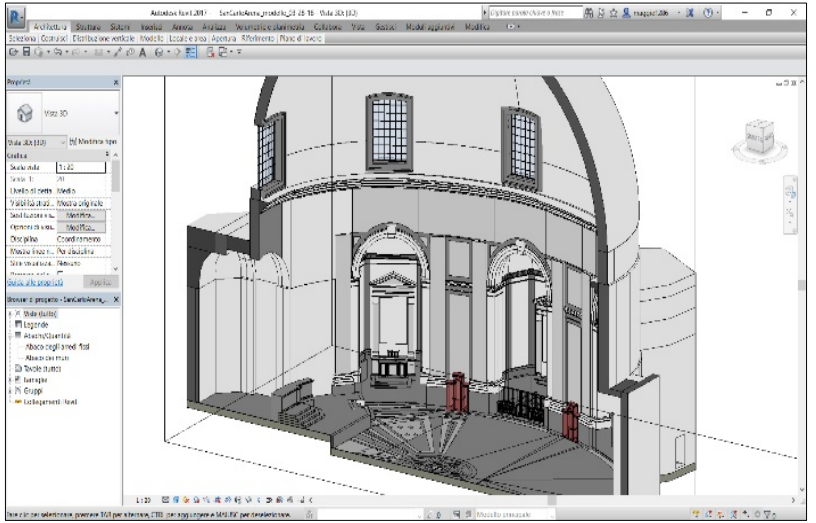

Figure 5. H-BIM model in Autodesk Revit

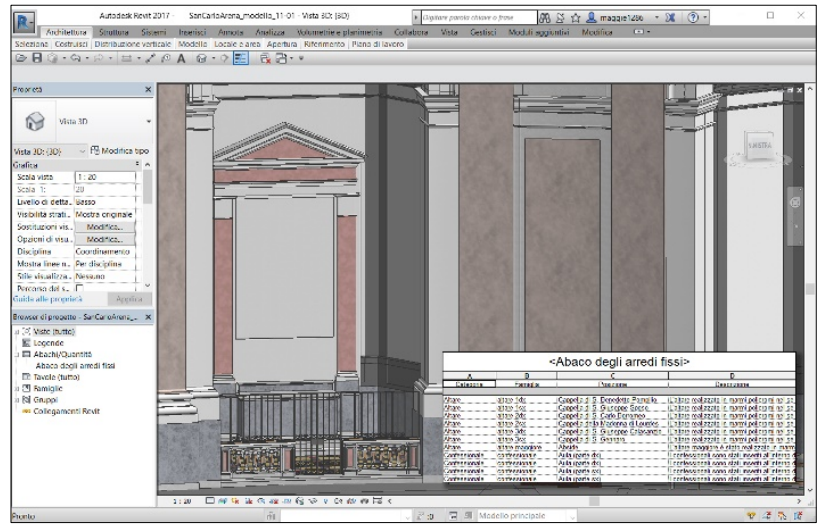

Figure 6. H-BIM model in Autodesk Revit with database of internal decorative apparatus.

moment of cultural growth that gives access to knowledge and details that are unattainable or excessively complex for traditional techniques. (M.P., S.S.)

\section{VIRTUAL EXPLORATION OF SPACE}

The HBIM digital model has given a rigorous documentation of the architectural text, through which to elaborate configurative geometric hypotheses.

To finalize the study of the artefact, as well as diffuse the knowledge of it, the documentation has been structured in such a way as to make it accessible not only to scholars, but also to various types of users. This is possible using specific software that allow to simulate an interactive visit of the digitally reconstructed spaces, proposing either an augmented reality (AR) or virtual reality (VR) to the user, with the aim being a more significant involvement of the public towards the architectural space and its peculiarities (through AR, the visitor can implement his own perception of reality overlapping contents of various types and, therefore, increasing those naturally perceptible, while with VR, the visitor becomes part of a non-existent reality, if not in a digital environment, allowing for an otherwise inaccessible accessibility).

It is well-known how the implementation of augmented reality projects starts with the digital processing of information to be returned to the virtual visitors. The output (digital threedimensional modelling, video, text, audio, photo montages or an integration of more than one) and the fruition mode will depend on the choice of the communication project (AR and/or VR), having the possibility to manage the degree of immersion or the levels of overlap between built reality and multimedia content.

A key role is played by the tools to support the communication project, whether they are screens to display multimedia content (computers or portable devices), or specific VR devices necessary to project the user directly into the digital scenario (visors, earphones, gloves, controllers).

For the Church of San Carlo all'Arena, it was decided to design a virtual tour of the internal space, based on the photographic data and three-dimensional modelling, implemented by information labels where historical-artistic data were considered fundamental for the understanding of the space.

This digital elaborate is connoted as an intermediate product between augmented and virtual realities, since it can be used both in immersive mode and through screens. In both cases, the visitor observes the space with a greater or less level of detail, without necessarily being physically on site. His point of view can either correspond to static and pre-established projective centres or be dynamic and relatively free, depending on the manipulation of the input data.

The support of the following was useful to realise the virtual tour: the 3D model produced in Revit, (for the digital restitution of the survey data), the 3D details obtained from the photo-modelling, the photographs acquired during the scanning phase from the integrated camera to the laser. To attribute the colourimetric data to the point clouds, the Faro Focus 3D scanner takes a number of photographs from which it reproduces the RGB data on the individual points acquired: these photographs completely cover the scene acquired, except for the shadow cone generated by the position of the scanner and are returned as single shots and as a unique equirectangular mosaic.

The first data processed concerns the photographs of the laser scanner, used in the equirectangular composition automatically extracted from Faro.

An equirectangular image is the projection on a plane of a spheriform scene. It is a particular geometric deformation deriving from precise projective rules useful for transforming a spatial scene into a plane image with a wide visual field $\left(360^{\circ}\right.$ horizontal and $180^{\circ}$ vertical, from $-90^{\circ}$ to $+90^{\circ}$ ). These images can be directly acquired thanks to the recent diffusion of panoramic cameras equipped with particularly wide-angle lenses,

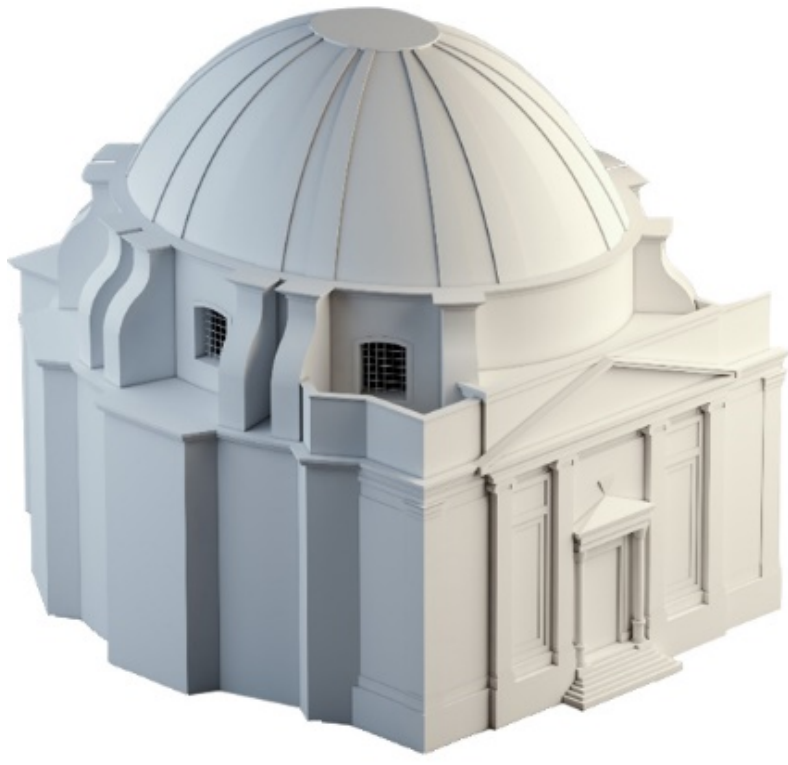

Figure 7. 3D model of San Carlo all'Arena 




Figure 8. Equirectangular image shot of the center of church.

or by elaborating, with specific software, the assembly of single traditional photographic shots, appropriately acquired with the help of panoramic heads that allow to establish and make univocal the centre of projection of the whole photographic mosaic. In the specific case of the photographs produced by the laser scanner used for this study, the photographic acquisition can be compared to that of a traditional camera with a panoramic head.

With a stitching and visualization software, it was possible to mount and then visualize the photographed space placing the observer's point of view at the centre of the scene, in exact correspondence to the acquisition point. Thus, the user can view the projection spherical photograph, devoid of any deformations, with the ability to navigate within $360^{\circ}$, experiencing a virtual tour from photographic images.

Specifically, after selecting some of the spherical images from among the different station points, it was decided to elaborate the communication project using the PANO 2VR software produced by Gnome Software.

Once the initial scene was established, it was necessary to construct the relationships between the various spherical photographs, placing, in correspondence to the respective projection centres, the hotspots useful for passing from one scene to another. It was then decided to support the navigation between the scenes by inserting the layout of the church (the layout is inserted as a static element that is always present, whatever the framing chosen by the user is), which is connoted as a navigator for the graphicization of hyperlinks - defined markers - placed at the different station points, so as to facilitate and constantly orientate the virtual visit.

To make the spherical navigation more dynamic, part of some scenes were replaced with the three-dimensional model, appropriately modifying the equirectangular photograph of the real space with the corresponding space obtained from the digital model.

Finally, with the support of the bibliographic research and the BIM informative model, the information that the user can freely choose to explore through the identification of further hotspots has been organized for the single scenes. For example, the transformations that the church has undergone after the restoration work have been included, the geometric detail of the design of the hall flooring and the high-resolution images of the paintings and sculptures on display in the individual chapels, associating specific descriptive cards (date, author, technique, description of the subject). (M.P.)

\section{CONCLUSION}

The use of the most up-to-date digital technologies for the representation and communication of the historical-architectural heritage represents a valid support for the knowledge and documentation of it. The digitization of the building through ITC, especially when aimed at broad consultation, is a way to implement the dissemination of the value of the cultural heritage of our contexts, rereading their specificities according to multiple interpretations.

From a scientific point of view, the acquisition of data through image-based or range-based instrumentation has made it possible to obtain a three-dimensional product and the transformation of which into a H-BIM model has made the data more manageable, as well as improved by further data. The experience of the reinterpretation in a geometric key has also made it possible to carry out further in-depth explorations that can be virtually used with mobile devices.

\section{ACKNOWLEDGEMENTS}

This paper is the result of research carried out in collaboration between the University of Naples Federico II and the University of Campania Luigi Vanvitelli.

We would like to thank the Research Centre Urban/Eco of the University of Naples Federico II for making available the tools necessary to carry out the research.

\section{REFERENCES}

Andreozzi, L., Barnobi, L., Colaiacovo, L., Giuffrida A., Santagati, C., 2004, Il modello nella rappresentazione delle opere architettoniche $e$ archeologiche, in Tecnologie per comunicare l'architettura, Atti del Workshop Earcom 2004, pag. 24-49, Ancona 20-21-22 maggio 2004, Clua Edizioni, ISBN 8887965-17-x.

Angelini, A., Gabrielli, R., 2013. Laser scanning e photo scanning. Tecniche di rilevamento per la documentazione $3 d \mathrm{di}$ beni architettonici ed archeologici, in Archeologia e Calcolatori 24-2013, Edizioni All’Insegna del Giglio, pp. 379-394.

Antonucci, S. 1979. Elementi di Geometria analitica, Napoli, Edizioni Liguori.

Apollonio, F. I., Ballabeni, A., Gaiani, M., Remondino, F., 2014. Evaluation of feature-based methods for automated network orientation, in The International Archives of the Photogrammetry, Remote Sensing and Spatial Information Sciences, vol. XL-5, 2014.

Bonacini, E., 2011. Nuove tecnologie per la fruizione $e$ valorizzazione del patrimonio culturale, Aracne Editrice S.r.l., ISBN 978-88-548-4290-8.

Cardaci, A., Versaci, A., 2012. Documentare per conservare: l'uso delle nuove tecnologie per la conoscenza, la salvaguardia e la comunicazione del patrimonio culturale armeno, in DisegnareCon, numero speciale doco 2012, ISSN 1828-5961.

De Luca, L., 2011. La fotomodellazione architettonica, 2011, Dario Flaccovio Editore, ISBN 978-88-579-0070-4.

di Luggo, A., Scandurra, S., 2016. La traduzione dal modello discreto al modello parametrico per la conoscenza del patrimonio architettonico nei sistemi HBIM, in DisegnareCon, volume 9 , n¹6 - giugno 2016, ISSN 1828-5961.

di Luggo, A., Pulcrano, M., Scandurra, S., Tarantino, C., 2017. Modellazione H-BIM e ricostruzione delle trasformazioni del 
costruito storico, in 3D Modeling \& Bim a cura di Empler T., 2017, Tipogafia del Genio Civile, ISBN 978-88-49645019.

Dotto, E., 2002. Il disegno degli ovali armonici, Le Nove Muse, Catania.

Donghi, D., 1925. Manuale dell'architetto. Torino, Unione tipografico-editrice torinese, vol. 1 parte I., p. 520.

Farella, E., Menna, F., Nocerino, E., Morabito, D., Remondino, F., Campi, M., 2016. Knowledge and valorization of historical sites through $3 d$ documentation and modeling, in ISPRS The International Archives of the Photogrammetry, Remote Sensing and Spatial Information Sciences. Volume XLI-B5, pp. 255262.

Fassi, F., Fregonese, L., Ackermann, S., De Troia, V., 2013. Comparison between laser scanning and automated $3 D$ modelling techniques to reconstruct complex and extensive cultural heritage areas, in International Archives of the Photogrammetry, Remote Sensing and Spatial Information Sciences, 40(5/W1), pp. 73-80.

Galizia, M., Santagati, C. 2012. Architettura e/è Geometria: dalla forma architettonica alla costruzione geometrica, in DISEGNARECON, vol. 5, n. 9, 2012, ISSN 1828-5961.

Giordano A., La geometria configurativa della cupola: San Carlo all'Arena, 1999. In Baculo Giusti A., di Luggo A., Florio R. (a cura di), Napoli versus coelum, la città e le sue cupole, Electa Napoli.

Golfieri, G., 2003. La Cappella degli Scrovegni, in CG Computer Gazette, computergrafica e beni culturali, Gennaio 2003, IHT Gruppo Editoriale.

Lo Brutto, M., Spera, M. G., 2011. Sperimentazione di procedure automatiche in fotogrammetria close-range per il rilievo di Beni Culturali, in Atti 15a Conferenza Nazionale ASITA, Reggia di Colorno 15-18 novembre 2011.

Magnano di San Lio, E., Galizia, M., Santagati, C., 2012. Rilievo e modellazione $3 D$ per lo studio delle chiese a pianta ovale in Sicilia: il caso di Santa Chiara a Catania, in DisegnareCon, numero speciale doco 2012, ISSN 1828-5961.

Migliari, R. 2003. Geometria dei modelli. Rappresentazione grafica e informatica per l'architettura e per il design, Roma, Kappa Edizioni, ISBN: 9788878905122.

Misiti, M., 2009. La fruibilità in rete del patrimonio culturale: un'analisi per il futuro, in ArcheomaticA, $n^{\circ} 0$ Novembre 2009, MediaGeo Editore, pp. 48-51.

Remondino, F., 2011. Rilievo e modellazione 3D di siti e architetture complesse, in DisegnareCon, dicembre 2011. ISSN 1828-5961.

Remondino, F., El-Hakim, S., 2006. Image-based 3D modelling: a review, in The Photogrammetric Record, 2006, Vol. 21.

Remondino, F., Nocerino, E., Toschi, I., Menna, F., 2017. A critical review of automated photogrammetric processing of large datasets. In: Int. Archives of Photogrammetry, Remote Sensing and Spatial Information Sciences, XLII-2/W5, pag.591599

Zerlenga, O., 1997. La forma ovata in architettura. Rappresentazione geometrica. Napoli, Cuen. 